\title{
Improving Intercultural Communication Skills through Teaching Academic Reading Texts: A Longitudinal Study
}

\author{
Jihad Hasan Azeez* \\ University of Samarra-College of Education \\ *Corresponding Author: Jihad Hasan Azeez, University of Samarra-College of Education

\begin{abstract}
Having developed a longitudinal quantitative repeated-measure design, the researcher tried to improve reading comprehension among Iraqi EFL students through developing intercultural competencies. To this end, 100 EFL Iraqi Students were selected as the participants of the study who were divided into 20 groups of 5 persons. All the groups took Slater, Millen, and Tyrie's (2009) Test Practice Academic (reading comprehension of Test 4) three times as the pretest, posttest, and delayed posttest. All the groups went through a twenty-session course. In effect, there was one session for each group per month, individually. Each session involved presentation, discussion, question-raising, explicating and clarifying the featured words, collocations as well as the cultural and ideological themes salient in each novel. The findings of the study showed that there were significant differences between the results of the pretest and the ones of both posttest and delayed posttest. Likewise, intensive reading seems to be crucial in improving the three variables of intercultural competence, reading comprehension, reading rate and vocabulary knowledge.
\end{abstract}

Keywords: intercultural communication, Intensive reading comprehension, repeated measure ANOVA,

\section{BACKGROUND}

English is considered as a foreign language in Iraq where learning English is limited to academic purposes especially for literacy skills, namely, reading comprehension or writing papers. Reading skill, in effect, has attracted the most attention where it is emphasized in both the contexts of the classrooms and other situations where the students are supposed to continue their studies in higher education (Carrell, 1989; Grabe \& Stoller, 2002). Reading skills are particularly significant for any student who is studying any major in the universities due to the fact that any subject needs to be intensively studied and comprehended. Likewise, reading comprehension seems to be crucial for Iraqi students who may not have any opportunity to use English orally but they certainly need to use English in the literacy skills.

There is no doubt regarding the significance of the reading skills among which to behave appropriately in the society, to understand different instructions of different devices, to write resume or to fill out different forms, reading road signs, to write and to answer to different emails, as well as to be a higher achiever in any situation are worth mentioning. In this regard, Davis (2014) warns that the lack of reading comprehension skills may result into inappropriate professional performance.

Contrary to the undisputable significance attached to the reading comprehension skills in the context of Iraq, it seems that teaching such skills is not satisfactory and still there is so much discontent on the part of both teachers and students. Reading seems to be defined differently by different researchers indicating the perspective followed.

Reviewing the history of reading comprehension teaching may explicate the intricate processes involved in reading comprehension skills. Safaaah (2014) views reading as "a process of getting the meaning of something written "and reading in a $2^{\text {nd }}$ language is considered as the processes for comprehending linguistic-related meaning. Here the most important factor appears to be the components of a text such as the letters, words, sentences, etc. Despite to Safaaah (2014), Harris (1956) regards reading as "the meaningful interpretation of (the) written verbal symbols (demanding) sensing, perceiving, achieving meaning, (and even) learning reacting ". Here the processes the readers go through seem to be emphasized. 
What is crucial is that reading is not a passive skill dependent to the written text, the letters or words. In fact, reading comprehension is a crucial skill in which there are multiple interactions among a variety of factors among which the cognitive processes, written text and context are worth mentioning. in this regard, Perfetti and Stafura (2014, p. 22)introduced the Reading Systems Framework - a model in which "word-to-text integration processes" are being utilized as a frameworktoexplore "local comprehension processes". Such a model emphasizes the connection between two systems of word recognition and comprehension in which vocabulary seems to be crucial (Perfetti \& Stafura, 2014).

Westwood (2012) underscores the background knowledge possessed by the learners as a starting point for filtering, interpreting, organizing and reflecting on the on-going information they my get from the passage. To him, reading comprehension demands an effective integration of a number of skills, namely, word identification, association between the new information andthe background knowledge, employing the effective strategies such as skimming, scanning, making prediction, identifying the main ideas and the supporting details, making inference.

The empirical research in the field of reading skill can be categorized into several types, namely, exploring single or multiple variables (e.g. Leeser,2007; Carretti, et al., 2014) correlational studies (Fernandes, et al., 2014), and exploring the role played by the instructional model (e.g. McKeown, Beck, \& Blake, 2009).

In effect, reading comprehension is analyzed by different researchers for whom several factors such as vocabulary knowledge (Laufer, \& Avaid-Levitzky, 2017; Perfetti \& Stafura, 2014; Quinn, et al., 2015; Van Steensel, et al., 2016; Zhang, 2012; Zhang, \& Yang, 2016), grammar knowledge (Leeser, 2007), extensive or intensive reading (Suk, 2017)or the individual factors (Lervåg, et al., 2019) and strategies training (Boulware- Gooden, et al., 2007; Hawkins, et al., 2010; McKeown, Beck, \& Blake, 2009) are among the factors influence the development of reading comprehension. The following sheds light on some of such studies.

One of the areas where reading comprehension is being investigated is through its components either as a single variable or multiple variables. Boulware- Gooden (2007) considers metacognitive strategies as important strategies in improving the process of reading comprehension since they "helps students to think about their thinking before, during, and after they read" (p. 70).

Hawkins et al. (2010, p. 903), on the other hand, explored the immediate influence of "two listening previewing strategies on reading comprehension and vocabulary knowledge". to this end 21 students were selected as the participants of the study who were exposed to three experimental conditions including a silent reading control condition, a listening previewing condition, and a listening previewing with vocabulary previewing condition" (Hawkins et al., 2010, p. 903).

In gathering the data, several instruments were utilized, i.e. reading-aloud the grade-level texts, 10 reading comprehension questions, and a vocabulary- matching task. The results of the study revealed that the three strategies were beneficial in improving reading comprehension. The study also showed that "vocabulary previewing component to listening previewing procedures" brings the greatest degrees of comprehension and vocabulary.

Having explored the impact of socioeconomic status on reading comprehension and vocabulary development, Lervåg et al. (2019) showed that socioeconomic status "had a direct influence on growth in both reading comprehension and vocabulary" where they are "partly mediated by school absence and nonverbal IQ" (Lervåg et al., 2019, p.1).

Having conducted a latent change score modeling, Quinn et al. (2015) explored the developmental relation between vocabulary knowledge and reading comprehension. The results of the study manifested that it is the vocabulary knowledge that determines the development of reading comprehension growth, and not the other way around.

Having employed a quasi- experimental research design, Suk (2017, p. 73) examined the effect of "an extensive reading approach on the reading comprehension, reading rate, and vocabulary acquisition of Korean university students studying English as a foreign language". To this end, two intact classes were uses in terms of two experimental and two control groups. The control classes went through a 
100- minute intensive reading instruction per week, and the experimental classes through a 70- minute intensive reading instruction followed by a 30- minute extensive reading instruction per week. The researcher showed that the extensive reading is an important factor in improving the three variables of reading comprehension, reading rate and vocabulary knowledge. the results of the study also showed the significant outperformance of the experimental groups comparing the control ones.

There are also many old studies which tried to explicate the role played by single variables such as background knowledge (e.g., Alexander \& Kulikowich, 1991),inference (e.g., Davey, 1988), cognitive and metacognitive strategy use (e.g., Meye, Brandt, \& Bluth, 1980), vocabulary (e.g., Stahl, Hare, Sinatra, \& Gregory, 1991), and word reading (e.g., Hood \& Dubert, 1983). The main trust of such studies was to develop the appropriate mediational programs in terms of instructional approaches.

Despite the undisputed significance of such studies in developing the appropriate methods and strategies in teaching reading comprehension; teaching reading comprehension seems to be controversial especially in a country such as Iraq where English is a foreign language but reading comprehension apparently plays a crucial role.

Having investigated the review of the related literature, the researcher understood that something is missing in the previous studies. We are repeatedly trying to explore the role played by single or multiple factors but here the role of situational context and sociocultural context and its mediational role in reading comprehension and making meaning is being ignored.

In this regard, having compared the impact of two instructional methods, Carretti et al. (2014) examined the development of reading comprehension among 159 pupils. To this end, they selected two instructional frameworks - one of them based on listening comprehension and the second one on reading comprehension. The two frameworks involved metacognitive strategies and working memory. It is worth mentioning that the two models were designed based on the "same abilities/processes strictly related to text comprehension, and particularly metacognitive knowledge and control, WM" (Carretti et al., 2014, p. 194). The findings of the study showed that the two methods are beneficial but the one related to reading comprehension was more successful.

In a different study, Garcia (1991) tried to explicate a number of ways to design and implement a range of tasks and activities using authentic Spanish language. The main thrust of his study was to equip the students with the required strategies to detect and comprehend the underlying sociocultural context of a reading text.

Lin (2002), on the other hand, explored the role played by the EFL learners' perception of the background knowledge and its impact on the processes of reading comprehension. Having employed a survey study, 400 EFL students were selected as the participants of the study. The results of the study showed that the proficiency level of the students are crucial for their perception in which the linguistic knowledge is fundamental for the lower levels and the conceptual and sociocultural knowledge for the higher levels.

Having conducted a case study, Yoo (2015) investigated the metacognitive strategies utilized by the case study in dealing with three texts with different genres. To this end, two instruments were utilized for gathering the data, that is, interviews and think- aloud protocols. YOO (2015) showed that genre is crucial in the processes of reading comprehension and the strategies being utilized.

Having combined reading strategies and social mediation, Gladwin and Stepp- Greany (2008, p. 687) made a comparison between the "Interactive Reading with Instructor Support model and traditional (direct- teaching/lecture format) instructional model" in terms of their impacts on reading comprehension. The findings indicated to the out performances of the students who were instructed through the Interactive Reading with Instructor Support model.

Having followed a revolutionary paradigm, Luke, Woods, and Dooley (2011, p. 157) introduced reading comprehension as a "cognitive, but also social and intellectual, phenomenon". They argued the previous perspectives regarding reading comprehension that "are insufficient for literacy education for diverse and marginalized students" (Luke, Woods, \& Dooley, 2011, p. 157). In particular, they state that: 
Comprehension does not necessarily entail verification of literal and inferred meanings, but critical analyses of their possible origins, motivations, and consequences through understanding of semiotic codes and pragmatic and interactional conventions (Luke, Woods, \& Dooley, 2011, p. 160).

Such a definition equips the researcher to include cognitive processes in order to consider the background knowledge in the processes of construction, maintaining, and evoking meaning. Such a definition also emphasizes the cultural dimension of reading comprehension for which field knowledge, content, and shared perspectives seem to be fundamental (Kintsch \& Greene, 1978). Beside to the cognitive processes involved in such a definition, social, intellectual and political dimensions are being highlighted (Luke, Woods, \& Dooley, 2011).

For a sustained achievement, teaching reading comprehension needs to surpass direct, reciprocal, or strategy-based instruction in order to implement engagement and participator teaching (Luke, Woods, \& Dooley, 2011). Here the focus needs to be given to the engagement of the students in such a way that the social world outside of the educational context is being tackled.

Such a perspective demands that the learners are being engaged "with community knowledge and institutions (and scrutinize the way) literacy works in everyday life, social institutions, and a scaffoldedand motivating engagement with the substantive intellectual fields of school subjects and world knowledge" (Luke, Woods, \& Dooley, 2011, p.162).

Engagement and participatory instruction seems to be what is called culturally based and critical approaches to reading which is also in line with intercultural communication. As an illustration, Olson (2002) views the differences between the educational contexts and students' everyday lives as the root of the differences observed in the achievement of different learners. In other words, it is not the ability differences which make a difference but the harmony or lack of harmony between schooling and everyday experiences of the learners. It is also in line with scientific and everyday concepts noted by Vygotsky.

It seems that the recent theories in the field of reading comprehension instruction emphasize the role played by the background knowledge and the cultural knowledge the learners bring with themselves to the educational contexts. Ketchum (2006, p. 22) focuses on "developing background knowledge about a target culture while applying a 3R model of reading strategies (Recognize, Research, Relate)to appropriate clues in a foreign text".

It should be noted that learning another language - whether as a second or foreign language - is too complicated to be explained through exploring one or several variables and reading comprehension is not excepted. Here we can provide a long list of the affective variables such as background knowledge, self-confidence, motivation, Willingness to communicate, genre familiarity, field knowledge, lexical and grammatical knowledge, context, etc. (e.g. Alexander \& Kulikowich, 1991), Davey, 1988; Ketchum, 2006;Meye, Brandt, \& Bluth, 1980; Stahl, Hare, Sinatra, \& Gregory, 1991; Hood \& Dubert, 1983).

Hence, it is simplistic to discuss that reading comprehension is being influenced by only one or two variables. We need to consider reading comprehension in its totality and make an account of at least the most important variables among which background and cultural knowledge the learners bring with themselves, social and cultural context in which reading comprehension is being taught and learned as well as the appropriate and inappropriate cognitive strategies utilized by the learners in the processes of reading comprehension seem to be fundamental.

Having considered such a context and by regarding the challenges and difficulties the Iraqi learners go through in reading comprehension processes, the researcher endeavored to pragmatically implement an engagement and participatory model in which the instruction is being planned and done according to the learners' background knowledge, native language features, gender, ethnicity, values, their weaknesses and strengths, their purposes for learning reading comprehension, strategies and skills related to reading comprehension, and political and cultural context of Iraq.

To this end, the following questions were raised: 
1. Is the treatment successful in improving the reading comprehension among the Iraqi EFL students?

2. Do the individual characteristics such as gender and age play any role? If so, how?

3. What are the differences among the three pre-test, posttest and delayed posttest?

\section{METHOD}

\subsection{Design of the Study}

The present study followed a quantitative repeated-measure design in which a group of 100 EFL Iraqi Students took a reading comprehension test three times (pre-test, posttest, and delayed posttest).

\subsection{Participants of the Study}

100 Iraqi EFL students were the participants of the study whose ages were between 19 and 36 from both genders. In fact, the participants composed of 47 female and 36 male EFL Iraqi Students.

\subsection{Materials}

In conducting the present study, the reading section of test 4 extracted from Slater, Millen, and Tyrie's (2009) Test Practice Academic. Centre for English Language in the University of South Australia. In effect, the reading test was selected for the pretest, posttest and the delayed posttest. In exploring its reliability, it was administered among 35 Iraqi EFL students with the similar level and backgrounds which lead to the index of 82 that was satisfactory.

The second source for the materials was several novels in which the students were supposed to read intensively and present their understanding through lecture, follow-up discussion, question-raising, and research. The covered novels included the following:

- The Little Old Lady Who Broke All the Rules by Catharina Ingelman Sundberg

- An Anonymous Girl by Greer Hendricks and Sarah Pekkanen

- On the Meaning of Life

- Before I Fall by Lauren Oliver

- A Gathering of Shadows by V. E. Schwab

- A Moveable Feast by Ernest Hemingway

- A Perilous Undertaking - Veronica Speedwell by Deanna Raybourn

- Uncommon Type by Tom Hanks

- Call of the Wild and White fang by Jack London

- Crazy Rich Asians by Kevin Kwan

It is worth mentioning that the selected novels were based on the criteria to include different genres and diverse cultural background in time and place.

\subsection{Procedures}

Having selected 100 Iraqi EFL student, the researcher divided the students into 20 groups of 5 persons. The groups were formed in such a way to include the students with diverse backgrounds including age, gender, beliefs, prophecy, etc. it is worth mentioning that before grouping the students took the pretest, i.e. Slater, Millen, and Tyrie's (2009) Test Practice Academic (reading comprehension of Test 4).

All the groups went through a twenty-session course. It should be noted that the present study was a longitudinal one developed through 20 months - from 22 November 2017 to 22 June 2019). Hence, there was one session for each group per month, individually. Moreover, each novel was covered during two months.

Each session was started with a presentation by a member of each group followed by discussion of other members. The members also raised their ambiguities, the featured words and collocations as well as the cultural and ideological themes salient in each novel. Here, the main role played by the 
instructor was to observe, lead and challenge the misunderstanding of the group in order to improve their comprehension.

It should be noted the first session was an introduction to the course and the last session the posttest was administered. Finally, the delayed test was conducted on July, 2019.

In analyzing the data, the results (scores) of the tests - pretest, posttest, and delayed-posttest - was put into SPSS which as examined through descriptive and inferential statistics. In analyzing the data, One-way ANOVA was utilized.

\section{RESUltS}

100 Iraqi EFL students participated in the present study who were divided into 20 groups of five persons. The study was finished in about two years during which the intercultural communication skills of the students were targeted and improved through intensive exposure to the authentic literary works. In the first step, all the students took the pretest as table 1 shows the descriptive statistics.

Table1. Descriptive statistics (Pretest-Gender\& Age)

\begin{tabular}{|c|c|c|c|}
\hline Variables & Code & Type & Frequency \\
\hline \multirow{3}{*}{ gender } & 1.00 & =female & 47 \\
\cline { 2 - 4 } & 2.00 & $=$ male & 53 \\
\hline \multirow{3}{*}{ age } & 1.00 & $=19-25$ & 65 \\
\cline { 2 - 4 } & 2.00 & $=26-30$ & 19 \\
\cline { 2 - 4 } & 3.00 & $=31-36$ & 16 \\
\hline
\end{tabular}

As table 1 shows the participants of the study included 53 male and 47 female students. The participants were also categorized in terms of age into three groups, namely, 19-25, 26-30, and 31-36. As the table shows there were 65 students with the age range between 19 and 25, 19 students between 26 and 30 years old and 16 with the ages between 30 and 36 .

Having followed a twenty-session course, all the participants took the posttest as table 2 shows. The table demonstrates that the mean of the three age groups was about 20 in the pretest, 28 in the posttest and almost 26 in the delay posttest. Moreover, the table shows that there are some trivial differences in the mean of the two genders and the three age groups in terms of time. As an illustration the females with the ages between 31 and 36 had the mean of 19 in the pretest, almost 27 in both posttest and delay posttest. The males with the ages between 31 and 36, on the other hand, showed the mean around 21 in the pretest, 28 in the posttest and almost 26 in the delay posttest.

Table2. Descriptive statistics (Test-Gender\& Age)

\begin{tabular}{|c|c|c|c|c|c|}
\hline & gender & age & Mean & Std. Deviation & $\mathrm{N}$ \\
\hline \multirow[t]{12}{*}{ pretest } & \multirow[t]{4}{*}{$=$ female } & $=19-25$ & 19.9706 & 2.20860 & 34 \\
\hline & & $=26-30$ & 20.8333 & 1.60208 & 6 \\
\hline & & $=31-36$ & 19.0000 & 1.52753 & 7 \\
\hline & & Total & 19.9362 & 2.07892 & 47 \\
\hline & \multirow[t]{4}{*}{$=$ male } & $=19-25$ & 20.3871 & 1.74504 & 31 \\
\hline & & $=26-30$ & 20.3846 & 1.80455 & 13 \\
\hline & & $=31-36$ & 21.1111 & 1.61589 & 9 \\
\hline & & Total & 20.5094 & 1.72786 & 53 \\
\hline & \multirow[t]{4}{*}{ Total } & $=19-25$ & 20.1692 & 1.99663 & 65 \\
\hline & & $=26-30$ & 20.5263 & 1.71167 & 19 \\
\hline & & $=31-36$ & 20.1875 & 1.86971 & 16 \\
\hline & & Total & 20.2400 & 1.91285 & 100 \\
\hline \multirow[t]{8}{*}{ posttest } & \multirow[t]{4}{*}{$=$ female } & $=19-25$ & 28.4412 & .74635 & 34 \\
\hline & & $=26-30$ & 27.5000 & 1.76068 & 6 \\
\hline & & $=31-36$ & 27.2857 & 1.49603 & 7 \\
\hline & & Total & 28.1489 & 1.12247 & 47 \\
\hline & \multirow[t]{4}{*}{$=$ male } & $=19-25$ & 28.4839 & .62562 & 31 \\
\hline & & $=26-30$ & 28.9231 & .64051 & 13 \\
\hline & & $=31-36$ & 28.0000 & .70711 & 9 \\
\hline & & Total & 28.5094 & .69677 & 53 \\
\hline
\end{tabular}


Improving Intercultural Communication Skills through Teaching Academic Reading Texts: A Longitudinal Study

\begin{tabular}{|c|c|c|c|c|c|}
\hline & \multirow[t]{4}{*}{ Total } & $=19-25$ & 28.4615 & .68641 & 65 \\
\hline & & $=26-30$ & 28.4737 & 1.26352 & 19 \\
\hline & & $=31-36$ & 27.6875 & 1.13835 & 16 \\
\hline & & Total & 28.3400 & .93441 & 100 \\
\hline \multirow[t]{12}{*}{ delay posttest } & \multirow[t]{4}{*}{$=$ female } & $=19-25$ & 26.4412 & .50399 & 34 \\
\hline & & $=26-30$ & 26.8333 & .40825 & 6 \\
\hline & & $=31-36$ & 26.8571 & .37796 & 7 \\
\hline & & Total & 26.5532 & .50254 & 47 \\
\hline & \multirow[t]{4}{*}{$=$ male } & $=19-25$ & 26.5161 & .50800 & 31 \\
\hline & & $=26-30$ & 26.6154 & .50637 & 13 \\
\hline & & $=31-36$ & 26.4444 & .52705 & 9 \\
\hline & & Total & 26.5283 & .50398 & 53 \\
\hline & \multirow[t]{4}{*}{ Total } & $=19-25$ & 26.4769 & .50335 & 65 \\
\hline & & $=26-30$ & 26.6842 & .47757 & 19 \\
\hline & & $=31-36$ & 26.6250 & .50000 & 16 \\
\hline & & Total & 26.5400 & .50091 & 100 \\
\hline
\end{tabular}

Figure 1 illustrates the performances of the three age groups during the time (pretest, posttest and delay posttest). As the figure shows the three age groups had the mean around 20 in the retest, 28 in the posttest and 27 in the delay posttest. Apparently, the most differences are related to the posttest which seems the youngest group outperformed and finally the three groups reached the same point in the delay posttest.

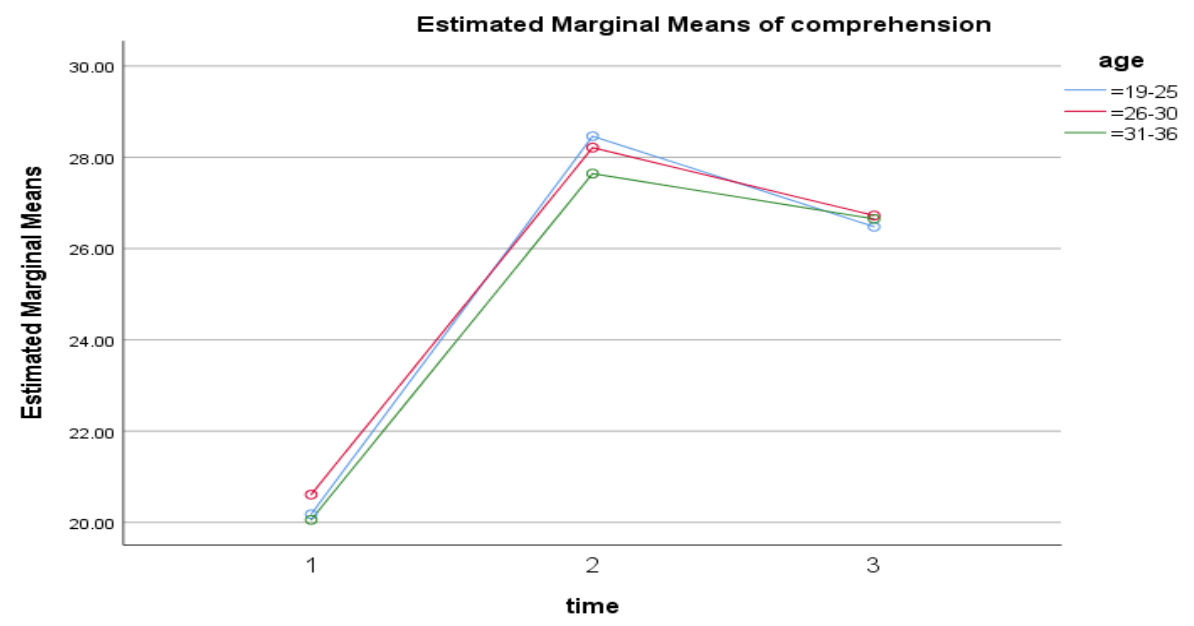

Figure1. Profile plots of the three age groups in terms of time

In a further step, the two genders were compared in terms of their performance in the three times of pretest, posttest and delay posttest. As figure 2 shows the two genders had apparently the similar performance in the pretest. in fact, both genders showed a score around 20 . In the posttest, the performance of both genders rose dramatically. Hence, the males outperformed slightly. Finally, the performance of both genders leveled off.

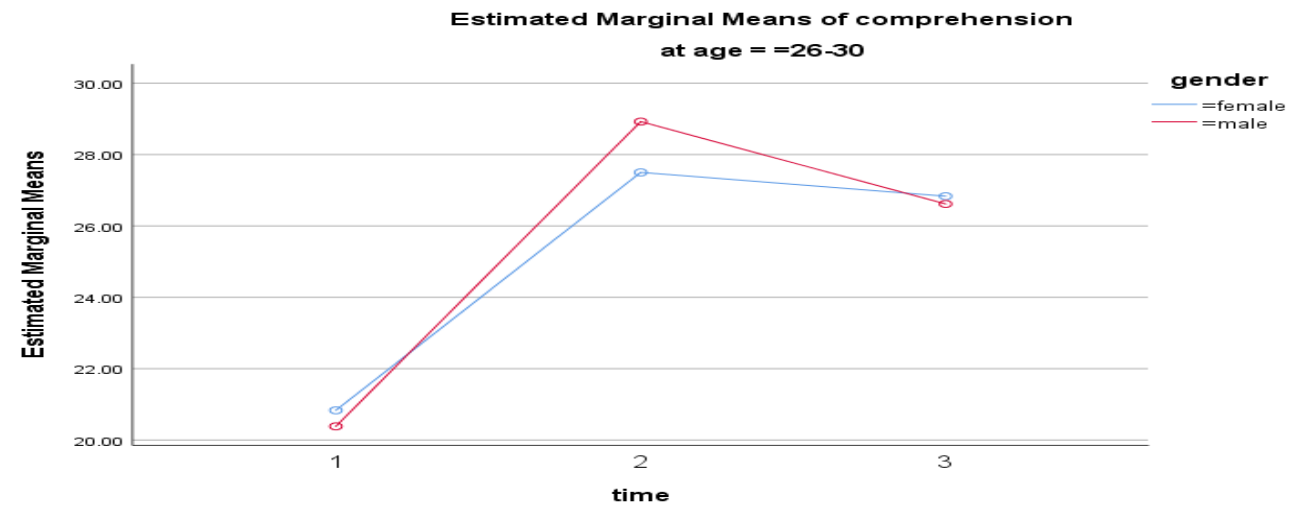

Figure2. Profile plots of the two genders in terms of time 
Likewise, sphericity and Mauchly's test evaluation was explored to see whether this holds-it is a requirement of repeated measure ANOVA. The significance level is 0.164 which is quite above the cut score $(\mathrm{p}>0.05)$. So the sphericity assumption is hold by our data.

Table3. Mauchly's Test of Sphericity

\begin{tabular}{|c|c|c|c|c|c|c|c|}
\hline \multicolumn{7}{|c|}{ Measure: comprehension } \\
\hline $\begin{array}{c}\text { Within } \\
\begin{array}{c}\text { Subjects } \\
\text { Effect }\end{array}\end{array}$ & Mauchly's W & $\begin{array}{c}\text { Approx. } \\
\text { Chi-Square }\end{array}$ & df & Sig. & \multicolumn{3}{|c|}{ Epsilon $^{\mathrm{b}}$} \\
\cline { 5 - 8 } & & & & & $\begin{array}{c}\text { Greenhouse- } \\
\text { Geisser }\end{array}$ & $\begin{array}{c}\text { Huynh- } \\
\text { Feldt }\end{array}$ & $\begin{array}{c}\text { Lower- } \\
\text { bound }\end{array}$ \\
\hline time & .551 & 55.430 & 2 & .164 & .690 & .734 & .500 \\
\hline
\end{tabular}

According to table 5, time has a $\mathrm{P}$-value (sig) of 0.000 which is quite below 0.05 . so we can label it as a statistically significant effect. The interaction effect, on the other hand, shows a p-value quite above the cut-score $(0.05)$. here the interaction effect - time-gender is 0.07 , time-age is 0.775 , time-genderage is 0.09 .

Table4. Tests of Within-Subjects Contrasts

\begin{tabular}{|c|c|c|c|c|c|c|c|}
\hline \multicolumn{2}{|c|}{ Measure: comprehension } \\
\hline Source & time & $\begin{array}{c}\text { Type III Sum } \\
\text { of Squares }\end{array}$ & df & $\begin{array}{c}\text { Mean } \\
\text { Square }\end{array}$ & F & Sig. & $\begin{array}{c}\text { Partial Eta } \\
\text { Squared }\end{array}$ \\
\hline \multirow{2}{*}{ time } & Linear & 1292.484 & 1 & 1292.484 & 692.036 & .000 & .880 \\
\cline { 2 - 8 } & Quadratic & 930.398 & 1 & 930.398 & 796.252 & .000 & .894 \\
\hline \multirow{2}{*}{ time * gender } & Linear & 6.206 & 1 & 6.206 & 3.323 & .072 & .034 \\
\cline { 2 - 8 } & Quadratic & 2.399 & 1 & 2.399 & 2.053 & .155 & .021 \\
\hline time * age & Linear & .953 & 2 & .476 & .255 & .775 & .005 \\
\cline { 2 - 8 } & Quadratic & 7.654 & 2 & 3.827 & 3.275 & .042 & .065 \\
\hline \multirow{2}{*}{ time * gender } & Linear & 9.245 & 2 & 4.622 & 2.475 & .090 & .050 \\
\cline { 2 - 8 }$*$ age & Quadratic & 8.621 & 2 & 4.311 & 3.689 & .029 & .073 \\
\hline Error(time) & Linear & 175.560 & 94 & 1.868 & & & \\
\cline { 2 - 8 } & Quadratic & 109.836 & 94 & 1.168 & & & \\
\hline
\end{tabular}

Figure 3 shows the performance of the two genders with the ages between 19 and 25. As the profile plots illustrate they had closely similar performance in which the performance of both females and males are being coincided especially in the posttest and delay posttest. In the pretest the females had the mean score of 20 and the males just over 20. both genders showed the mean just over 28 in the posttest, and just over 26 in the delay posttest. Hence, the gap either between the pretest and posttest or pretest and delay posttest is widened.

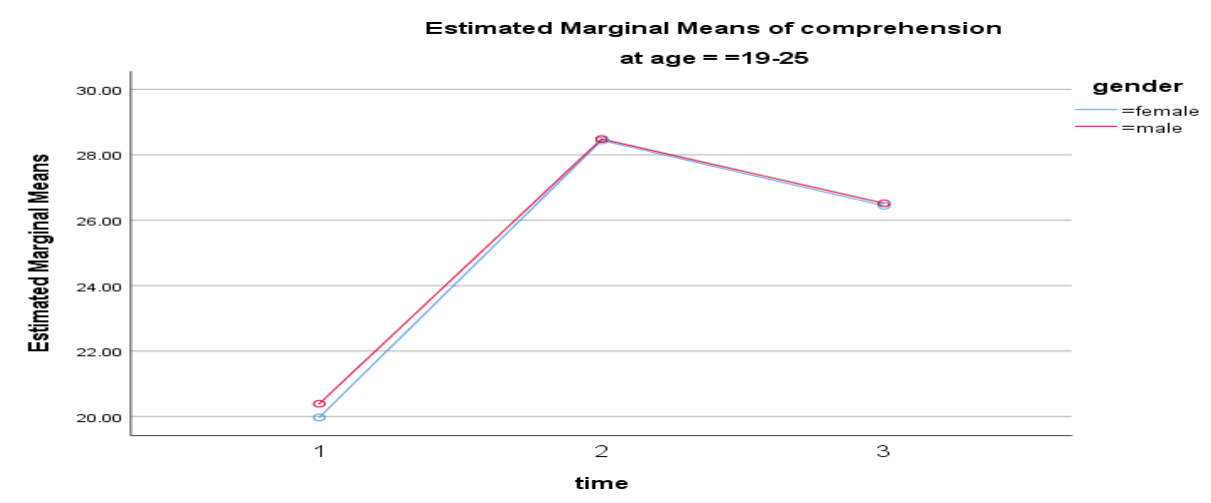

Figure3. Profile plots of the interaction between gender and time in the age group 1 (19-25)

Figure 4, on the other hand, illustrates the performance of the two genders with the ages between 26 and 30. A more detailed look at the graph reveals that the difference between the two genders is widened in the posttest. Contrary to the partial difference between the two genders in the posttest, the 
performance of both females and males are being coincided in the delay posttest in which both reached the mean about 27 . In the pretest both females and males had the mean score around 21 . In the posttest, the gap between the two genders is partially widened. Hence, the females showed the mean about 27 and the males a mean around 29.

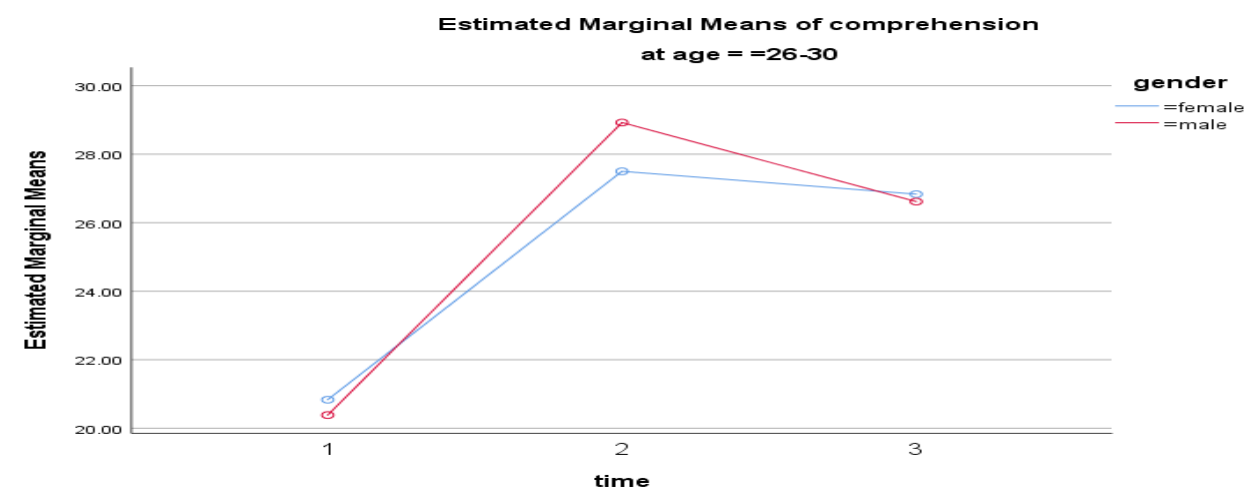

Figure4. Profile plots of the interaction between gender and time in the age group 2 (26-30)

Figure 5 reveals the performance of the two genders with the ages between 31 and 35 . As the profile plots showsthere are partial gap between the two genders in the three times. In effect, the females had the mean score about19 and the males about 21 , in the pretest.in the posttest, on the other hand, the females showed the mean about 27 and the males the mean about 28 . In the posttest, the gap between the two genders seems to be narrowed. In the delay posttest, the mean of the females is just over 27 and the mean of the males just below 27 .

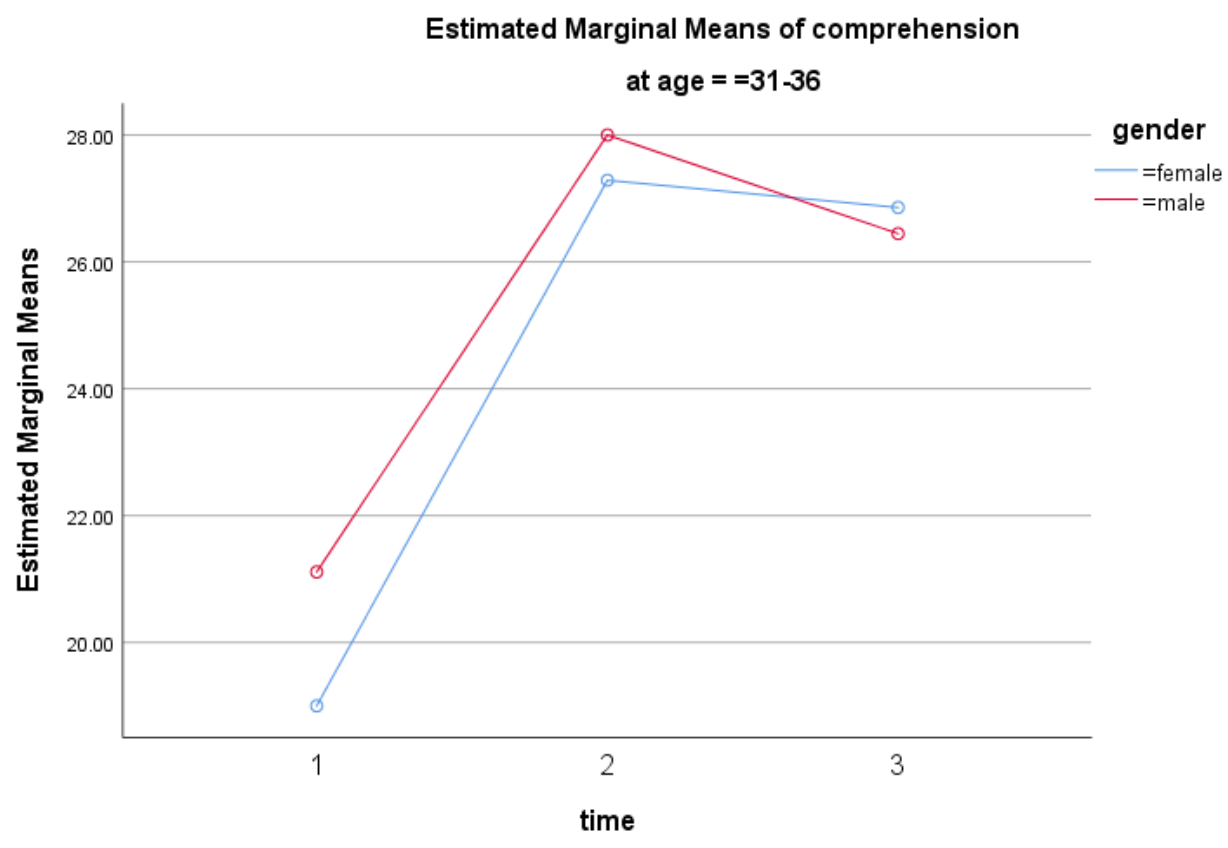

\section{DISCUSSION \& IMPLICATION}

Having tried the research, the researcher answered the three raised questions. The results of the descriptive statistics and repeated measure ANOVA showed significant differences before the treatment and after the treatment was given. In fact, it was found the performances of the participants have been significantly changed during the time.

It seems that improving intercultural competence, regardless of cultural background of the students, equip the students in order to engage dialogically with a text in another language including English. In other words, reading romans and stories helped the students in order to improve their intercultural competence whose development facilitated engagement and negotiation processes for reading comprehension skills in part of the Iraqi EFL students. Such findings are in harmony with other studies such as Hellerstein-Yehezkel (2017), Lin (2004) or Nie (2017). 
Lin (2004) is one of the researchers who numerates the prerequisite elements for reading comprehension, namely, "linguistic knowledge, cultural background knowledge, language skills, and intelligent elements" (Lin, 2004, p. 1). It appears that the present study has embarked on several elements simultaneously, i.e., the knowledge of the target language (vocabulary, structure, culture and language skills) through the processes of reading comprehension. As it is indicated by Lin (2004, p. 8), any social communication including reading comprehension in a foreign language demands its related and appropriate "thought pattern, value, custom, and way of life". Ma (1995) also refers to the crucial influence of background and cultural knowledge.

Having investigated the influence of reading task journals on students' intercultural study through novel reading, Nie (2017) showed that reading journals facilitates intercultural communication of the students through which they cultivate the cultural differences and dimensions in reading.

Such findings recall Rogers' (2004, p. 2) distinction between "hard and soft structures to language" where hard structures referto the linguistic system and soft structures to the function of language. Hence, we need to resort to Halliday's (1975) argument in which he argues

The viewpoint we are taking [with regard to language] is a functional one. We shall relate the meaning, in turn, to linguistic function, to the functions that language is made to serve in the life of the growing child ... this gives us some insight into why the adult language has evolved in the way it has ... we can see the adult linguistic study is structured in a way which reflects very closely its functional origins. (p. 8)

Likewise, reading comprehension demands cultural and background knowledge as well as intercultural communication skills such as "distinctive ways people talk, read, write, think, believe, value, act, and interact with things and other people to get recognized" (Gee, 2004, p. 39).

Having developped Lewis and Ketterthe's (2004) notion, we can assume that reading comprehension as a social-mental activity for which intercultural interactions among people and their tools and technologies are crucial.

The results of the study, on the other hand, revealed that the observed differences between the two genders, among the three age groups and the interaction of them with the time are not significant. Likewise, the results of the study are against the findings of some researchers such as Kamari, Gorjian, and Pazhakh (2012, p. 759) for whomgender "implicitly presents the social and contextual expectations each society put on part of each gender culturally as well as socially".

It is recommended that the instructors consider the social and cultural ideologies and backgrounds prevailed in the reading comprehension texts and equip the students with the appropriate mental and social skills and strategies in order to engage dialogically and dialectically with the texts.

Here, the role, type and procedures of mediation cannot be ignored. As an illustration, the presented materials and the fictional and non-fictional romans played the role of mediation which facilitated the processes of intercultural communication skills and as a result the reading comprehension processes.

In a nutshell, the results of the study seem to be concerned of different people who are related to teaching or learning any foreign or second language such as teachers, teacher trainers, students, curriculum developers, etc. Hence, we can implement intensive or extensive reading comprehension along the appropriate activities such as presentation, finding the collocations, the prevailed ideology or culture, discussion, etc.

\section{REFERENCES}

[1] Boulware- Gooden, R., Carreker, S., Thornhill, A., \& Joshi, R. M. (2007). Instruction of metacognitive strategies enhances reading comprehension and vocabulary achievement of third- grade students. The Reading Teacher, 61(1), 70-77.

[2] Carretti, B., Caldarola, N., Tencati, C., \& Cornoldi, C. (2014). Improving reading comprehension in reading and listening settings: The effect of two training programmes focusing on metacognition and working memory. British Journal of Educational Psychology, 84(2), 194-210.

[3] Carretti, B., Caldarola, N., Tencati, C., \& Cornoldi, C. (2014). Improving reading comprehension in reading and listening settings: The effect of two training programmes focusing on metacognition and working memory. British Journal of Educational Psychology, 84(2), 194-210. 
[4] Fernandes, S., Querido, L., Verhaeghe, A., \& Araújo, L. (2018). What is the relationship between reading prosody and reading comprehension in European Portuguese? Evidence from grades 2 to 5. Journal of Research in Reading, 41, S102-S129.

[5] Garcia, C. (1991). Using authentic reading texts to discover underlying sociocultural information. Foreign Language Annals, 24(6), 515-526.

[6] Gee, J. P. (2004). Discourse analysis: what makes it critical? In: R. Rogers (Eds.), An introduction to critical discourse analysis in education (pp. 19-50). NY: Routledge.

[7] Gladwin IV, R. F., \& Stepp- Greany, J. (2008). An Interactive, Instructor- Supported Reading Approach vs. Traditional Reading Instruction in Spanish. Foreign language annals, 41(4), 687-701.

[8] Harris, A. J. (1956). How to increase reading ability; a guide to developmental and remedial methods. NY: David McKay.

[9] Hawkins, R. O., Musti- Rao, S., Hale, A. D., McGuire, S., \& Hailley, J. (2010). Examining listening previewing as a classwide strategy to promote reading comprehension and vocabulary. Psychology in the Schools, 47(9), 903-916.

[10] Hellerstein-Yehezkel, D. (2017). The path to reading comprehension through intercultural competence in the multicultural EFL classroom. Language and Intercultural Communication, 17(3), 323-343.

[11] Ketchum, E. M. (2006). The cultural baggage of second language reading: An approach to understanding the practices and perspectives of a nonnative product. Foreign Language Annals, 39(1), 22-42.

[12] Laufer, B., \& AVIAD-LEVITZKY, T. A. M. I. (2017). What Type of Vocabulary Knowledge Predicts Reading Comprehension: Word Meaning Recall or Word Meaning Recognition?. The Modern Language Journal, 101(4), 729-741.

[13] Leeser, M. J. (2007). Learner- based factors in L2 reading comprehension and processing grammatical form: Topic familiarity and working memory. Language learning, 57(2), 229-270.

[14] Lervåg, A., Dolean, D., Tincas, I., \& Melby- Lervåg, M. (2019). Socioeconomic Background, Nonverbal IQ, and School Absence Affects the Development of Vocabulary and Reading Comprehension in Children Living in Severe Poverty. Developmental science, e12858.

[15] Lin, W. (2004). A study on cross-cultural barriers in reading of English. Asian EFL Journal, 6(2), 1-10.

[16] Lin, Z. (2002). Discovering EFL learners' perception of prior knowledge and its roles in reading comprehension. Journal of research in Reading, 25(2), 172-190.

[17] Luke, A., Woods, A., \& Dooley, K. (2011). Comprehension as social and intellectual practice: Rebuilding curriculum in low socioeconomic and cultural minority schools. Theory Into Practice, 50(2), 157-164.

[18] McKeown, M. G., Beck, I. L., \& Blake, R. G. (2009). Rethinking reading comprehension instruction: A comparison of instruction for strategies and content approaches. Reading Research Quarterly, 44(3), 218253.

[19] McKeown, M. G., Beck, I. L., \& Blake, R. G. (2009). Rethinking reading comprehension instruction: A comparison of instruction for strategies and content approaches. Reading Research Quarterly, 44(3), 218253.

[20] Nie, Y. (2017). Facilitating Intercultural Study through Novel Reading - The Application of Reading Task Journals. Theory and Practice in Language Studies, 7(6), 436-442.

[21] Olson, D. R. (2002). There are x kinds of learners in a single class: Diversity without individual differences. Stirring the waters: The influence of Marie Clay, 17-25.

[22] Perfetti, C., \& Stafura, J. (2014). Word knowledge in a theory of reading comprehension. Scientific Studies of Reading, 18(1), 22-37.

[23] Quinn, J. M., Wagner, R. K., Petscher, Y., \& Lopez, D. (2015). Developmental relations between vocabulary knowledge and reading comprehension: A latent change score modeling study. Child development, 86(1), 159-175.

[24] Rogers, R. (2004). An introduction to critical discourse analysis in education. London: Rutledge.

[25] Suk, N. (2017). The effects of extensive reading on reading comprehension, reading rate, and vocabulary acquisition. Reading Research Quarterly, 52(1), 73-89.

[26] van Steensel, R., Oostdam, R., van Gelderen, A., \& van Schooten, E. (2016). The role of word decoding, vocabulary knowledge and meta- cognitive knowledge in monolingual and bilingual low- achieving adolescents' reading comprehension. Journal of Research in Reading, 39(3), 312-329.

[27] Westwood, P. (2012). Reading and learning difficulties. David Fulton Publishers.

[28] Yoo, M. S. (2015). The influence of genre understanding on strategy use and comprehension. Journal of Adolescent \& Adult Literacy, 59(1), 83-93. 
Improving Intercultural Communication Skills through Teaching Academic Reading Texts: A Longitudinal Study

[29] Zhang, D. (2012). Vocabulary and grammar knowledge in second language reading comprehension: A structural equation modeling study. The Modern Language Journal, 96(4), 558-575.

[30] Zhang, D., \& Yang, X. (2016). Chinese L2 learners' depth of vocabulary knowledge and its role in reading comprehension. Foreign Language Annals, 49(4), 699-715.

Citation: Jihad Hasan Azeez. "Improving Intercultural Communication Skills through Teaching Academic Reading Texts: A Longitudinal Study" International Journal of Humanities Social Sciences and Education (IJHSSE), vol 7, no. 2, 2020, pp. 58-69. doi: http://dx.doi.org/10.20431/2349-0381. 0702009.

Copyright: (C) 2020 Authors. This is an open-access article distributed under the terms of the Creative Commons Attribution License, which permits unrestricted use, distribution, and reproduction in any medium, provided the original author and source are credited. 